Portland State University

PDXScholar

2014

\title{
Children of Alcoholics: How Patterns and Perceptions of the Past Affect the Future
}

Lindsey Anne Cochran

Portland State University

Follow this and additional works at: https://pdxscholar.library.pdx.edu/honorstheses

Let us know how access to this document benefits you.

\section{Recommended Citation}

Cochran, Lindsey Anne, "Children of Alcoholics: How Patterns and Perceptions of the Past Affect the Future" (2014). University Honors Theses. Paper 53.

https://doi.org/10.15760/honors.47

This Thesis is brought to you for free and open access. It has been accepted for inclusion in University Honors Theses by an authorized administrator of PDXScholar. Please contact us if we can make this document more accessible: pdxscholar@pdx.edu. 
Children of Alcoholics: How Patterns and Perceptions

of the Past Affect the Future

\section{by}

\section{Lindsey Anne Cochran}

An undergraduate honors thesis submitted in partial fulfillment of the

requirements for the degree of

Bachelor of Science

in

University Honors

and

Child \& Family Studies

Thesis Adviser

Jana L. Meinhold, PhD

Portland State University 


\begin{abstract}
Parental alcoholism and its effects on children has been a problem widely researched for years. This thesis seeks to find the patterns and roles that are established for children living with parental alcoholism and if/why these patterns are maintained into the individual's adulthood. In doing so, parental alcoholism and its effects on children and adult children will be examined through the lenses of symbolic interactionism and family systems theory. Several concepts that affect roles and patterns are discussed, some of the more prominent being: a) symbols, b) circular causality c) feedback loops, and d) roles. Through an in depth theoretical analysis, the implications that these findings have on families and those working with families in a professional setting are discussed.
\end{abstract}

\title{
Introduction
}

\section{The Problem: Parental Alcoholism}

Over the past few decades, the problem of parental alcoholism has been widely researched, and countless consequences have been found for those who abuse alcohol in a family setting. Alcoholism in the family is not only harmful physiologically for the user, but has many psychological and emotional effects surrounding the user's spouse, children, extended family, parents, friends, coworkers, and so on. Alcohol is extremely easy to obtain in the United States, as it carries only an age requirement and is widely available. Alcohol can be purchased at a variety of venues, for a relatively reasonable price, and is advertised almost everywhere we look. People drink alcohol for many different reasons, whether it be at a party with friends, or just to "unwind" after a long day at work. The issue of alcoholism is social, legal, emotional, and physical, and affects more people than the user is likely aware. 
The effects of parental alcoholism requires a deeper look into the establishment of roles and patterns that these Children of Alcoholics (COAs) generally pick up and live out. One of the reasons that I am particularly interested in this topic is because I myself am an Adult Child of an Alcoholic (ACOA). As a child, I adopted a role that seemed to completely envelop everything I did. As an adult, that role continues to show up and define me, even though I have been long removed from the situation that forced me into that particular role in the first place. In this paper, I will explore the relationship between the roles and patterns that are established among COAs and the maintenance of these patterns as individuals become ACOAs. To analyze this relationship, I will be using symbolic interactionism theory and family systems theory and will apply these theories to find any theoretical implications related to my research question.

\section{Overview of Literature}

\section{Defining Alcoholism}

There are numerous definitions of alcoholism that can be explored depending on one's perspective and what one hopes to accomplish through their definition. For my purposes, I will define alcoholism with the Mayo Clinic's (2012) definition. This dictionary defines alcoholism as, "a chronic and often progressive disease that includes problems controlling your drinking, being preoccupied with alcohol, continuing to use alcohol even when it causes problems, having to drink more to get the same effect (physical dependence), or having withdrawal symptoms when you rapidly decrease or stop drinking. If you have alcoholism, you can't consistently

predict how much you'll drink, how long you'll drink, or what consequences will occur from your drinking." This extremely comprehensive definition is helpful because it includes all facets of the disorder - the physiological, social, and psychological effects. Another important aspect to note about this particular definition is that it includes the word dependence. This word is crucial 
to the definition because it defines alcoholism as more than just someone who drinks on a semiregular basis. The term dependence is accompanied later by the symptoms of withdrawal, which is the necessary indicator in order to diagnosis someone with substance dependence (Fischer, Lyness, \& Engler, 2009).

\section{Consequences of Alcoholism}

Alcoholism, specifically long-term alcoholism, can negatively affect the body in numerous ways. The areas of the body that are most affected by alcoholism are the liver and immune system, followed by the cardiovascular and skeletal systems - this being said, alcoholics can suffer from various cardiac problems, hemorrhage, cancer, renal failures, neurological degeneration, and sudden death (Dingledine, 2000). COAs will likely witness some or many of these effects on the alcoholic parent(s).

Another effect that alcoholism has, specifically on COAs, is that the risk for COAs to develop alcoholism is much greater than that of non-COAs. Monuteax and Feighner (2000), found that a COA is twice more likely to develop alcoholism as an adult than a non-COA, whereas adolescents exposed to parental alcoholism were three times more likely to develop alcoholism. This may be because drinking alcohol is what the COA had modeled for them as a coping mechanism, and they do not know how to live as an adult any other way. Alternatively, it could be due to the psychological pain of their childhood, or a combination of these plus other outside factors such as genetic predisposition.

Maes (1998) claims that it is common for two alcoholics to marry each other - a process called assertive mating. This way, adults do not need to worry about their spouse getting in the way of their alcohol dependence. Hussong et al. (2008) shows that several factors regarding 
COAs are exaggerated when there are two alcoholic parents present in the household. For example, COAs with two alcoholic parents are shown to have greater externalizing symptoms due to the heightened level of stress in their home. Similarly, they exhibit greater internalizing symptoms such as lower social competence, usually due to the fact that when there are two alcoholic parents, there is a greater chance that the primary caregiver is an alcoholic.

\section{Social and Legal Impacts of Alcoholism}

One question that may be presented is why someone would choose to consume alcohol in the first place, and how it could then lead to alcoholism. Although the legal age of alcohol use in the United States is twenty-one, this is not the age at which the majority of individuals try alcohol for the first time. According to the National Institute on Alcohol Abuse and Alcoholism, the average age of the first use of alcohol was fourteen years old in 2003, as compared to seventeen in 1965 . This being said, it was also reported that those who tried alcohol before the age of fifteen were four times more likely to develop alcoholism sometime in their life. This is alarming due to the fact that this means that the majority of children are going to be four times more likely to develop alcoholism than they were in the past. This also shows us that children are starting to try alcohol younger, and that it is likely becoming more socially acceptable to begin drinking under the legal age, further lengthening the time in which young people can establish patterns with alcohol.

For many, alcohol use begins in the context of social interaction. It can also start as a way to calm nerves after a rough day. Perhaps one of the most dangerous and easy ways to develop alcoholism is when a person is using alcohol as a form of medication. People can selfmedicate for a variety of different reasons, one of which is clinical depression. When a person 
develops alcoholism due to depression, this is known as a dual diagnosis (Dingledine, 2000). A dual diagnosis can occur when anyone develops a substance dependence that coexists with an underlying psychiatric disorder. Psychiatric expenses can oftentimes be extremely pricey, and one may choose alcohol over medication simply due to easy accessibility and low price or due to bias about seeking psychiatric support. One may also turn to alcohol because they are not aware they are battling anxiety or depression, or have not been diagnosed. However, alcohol itself is a depressant, and alcohol taken in large quantities as a form of self-medication may only worsen the depression symptoms of the individual (Manninen, Poikolainen, Vartiainen, \& Laatikainen, 1996).

As a society, we also have many laws surrounding the appropriate use and distribution of alcohol. In many states, alcohol can only be sold on certain days and between certain times. Some states require that liquor not be sold in supermarkets or other convenience stores. One of the most widely known laws surrounding alcohol (aside from the age requirement) is that no one is permitted to drink while driving. All states have adopted that $0.08 \%$ is the legal limit for operating a motor vehicle for drivers over twenty-one, and those who do not comply with this law may be arrested or lose their driver's license (Center for Disease Control and Prevention, 2013). It is interesting to note that many people seem not to deem a friend or family member as an "alcoholic" until they have broken one of the laws above. For example, someone may have been an alcoholic for several years, yet until they break the law and possibly receive a DUI, their family will not address the problem. That being said, it seems that the social and legal implications of alcoholism are intertwined to some degree. 


\section{Gender Stigmatization of Alcoholics}

Research suggests that female alcoholics are more stigmatized by society due to the societal roles and standards that have been placed on women. Women may be more isolated and attempt to hide their alcoholism more so than men (Schmidt, Klee, \& Ames, 1990). This research also suggests that women suffer more greatly from the physiological effects of alcoholism. In the same study, it was found that most people believe that maternal alcoholism has a greater impact on children than paternal alcoholism. It can likely be assumed that the societal roles placed on women such as "the nurturer" and "the caregiver" are some of the reasons behind this stigmatization. Schmidt et al. (1990) also found that women with alcoholism experience more depression and suicide attempts than their male counterparts, which may be due to the fact that women with alcoholism seem to be much more ostracized in society, or the cooccurrence of dual diagnosis.

\section{Children of Alcoholics (COAs) and their Roles in Families}

There has been ample research done on families with substance abuse (primarily alcoholism) showing distinct roles that are established. Due to the fact that these roles are adopted as survival mechanisms for the individual, it is often hard to identify COAs in everyday society. It is normal for families and their individual members to have roles (caregiver, disciplinarian, etc.), but the roles in an alcoholic family system can often be more rigid and strained (Vernig, 2011). As the children oftentimes take on roles, the adults in the family play certain roles as well. These roles are known as the dependent and the enabler, or codependent. The roles of the children in these alcoholic families are most commonly known as: the family hero, the scapegoat (delinquent), the lost (invisible) child, and the mascot (clown). These roles were originally presented by Wegscheider-Cruse in 1989. In general, it seems that Wegscheider- 
Cruse and Steinglass are both very prominent in the literature when it concerns roles of COAs, and there is ample literature discussing these different roles and how they interact with each other. The qualities and patterns identified by each role are important to explore, starting with the dependent.

The dependent can also be known as the alcoholic parent in the family. This person brings stress to the family and oftentimes blames others for their alcohol use. They often use manipulation tactics to get what they want and also deny the fact that they have an alcohol problem (Smith \& Hamon, 2012). The enabler, or codependent, is usually the spouse of the alcoholic, but this role can also be adopted by the oldest child in the family. The enabler's job is to make sure that the dependent does not reap the consequences of their alcoholism. For example, the enabler may encourage the children in the family not to fight with the dependent when they have been drinking. They may also give excuses to members of the extended family in order to hide the alcoholism.

The hero is most often the firstborn child of the family. This person is usually a great student who always seems to have everything under control. This role may be hard to give up due to the fact that it has many rewards. For example, the hero is oftentimes seen as the "perfect child" of the family. In many ways, this child is responsible for making the family appear to be normal. Heroes are oftentimes the hardest COAs to detect for outsiders because they truly appear to be well-adjusted and supported. They tend to be overachievers, and are oftentimes extremely popular, athletic, and/or intelligent. This child oftentimes becomes "a serious little adult while their childhood passes them by," which may also involve some level of parentification (Gilbey, 2001, p. 7). They may have difficulty expressing their feelings and feel the need to constantly be in control. 
The scapegoat, or delinquent, is often a middle child, and tends to manifest the dysfunction of their family in some way. They may do poorly in school or may act out physically. This child acts this way in order to turn the attention away from the alcoholic and onto themselves. COAs that are scapegoat children may be easier for outsiders to recognize because they are the ones that typically manifest negative behavior. The lost or invisible child is also typically a middle child. The lost child tends to stay away from family drama in order to lessen any tension. They may become reclusive and spend hours in their rooms, keeping to themselves. These children do not tend to deal with their emotions, leaving them more susceptible to emotional illness. They may go unnoticed because they are neither leaders nor rebellious; they instead appear shy or withdrawn (Gilbey, 2001). Finally, the mascot, or clown, is typically the youngest child in the family. This child uses humor to lessen the tension in the household. They may appear to never take things seriously and/or make a joke out of every situation. They thrive when they are the center of attention and are usually well liked because of their good sense of humor. These roles are generally thought to be ever-present in a family with alcoholism; this means that all roles are being played out in some way or another. For example, if there are only two children in a family, these children may share a combination of these roles as needed. The most salient role for the COA would be the role that best defines them and that they must devote the most amount of time to.

\section{Behavioral and Psychological Patterns of COAs}

There has also been research done on how COAs tend to manifest the problems that are going on within their home. Research suggests that COAs tend to show certain behavioral and psychological patterns which can indicate to outsiders that something is wrong in the home. Some children's patterns may manifest behaviorally, which is typically more apparent than the 
more subtle psychological patterns. Robinson (1989) describes ten common behavioral patterns exhibited by COAs in the school setting: 1) difficulty concentrating, 2) persistent absenteeism, 3) poor grades and/or failure to turn in homework, 4) low scores on standardized tests, 5) sudden behavior change, 6) signs of neglect or physical/sexual abuse, 7) compulsive behaviors, 8) shyness or withdrawal from other children, 9) quarrelsome or uncooperative behavior with teachers and classmates and 10) constant health problems. These problems are frequently reported in schools because it is the child's way of manifesting the problems that they are having at home. Oftentimes outside sources need to be brought in for COAs due to the difficulties that they have in school.

Robinson (1989) also describes ten common psychological patterns that are exhibited by COAs. These patterns may be more subtle in nature and therefore harder to identify, but are just as significant as the more behavioral patterns. These psychological patterns include: 1) low selfesteem, 2) anxiety, 3) easily embarrassed, 4) suppressed anger, 5) perceive problems as beyond their control, 6) poor coping skills, 7) prone to depression, 8) unreasonably fearful, 9) sad and unhappy, and 10) difficulty adjusting to change in routines.

These behavioral and psychological patterns likely vary depending on the identified role of the child. For example, the child identified as the hero in the family could likely exhibit more psychological patterns than the scapegoat who may stick with a more behavior route in order to get more attention. These patterns are important because they help us to see how the adoption of the roles described earlier can impact the child both behaviorally and psychologically. 


\section{Role Application Controversy}

There has been some controversy among scholars when it comes to how easily the roles discussed above can be applied to real life situations. Vernig (2011, p. 540) questions the ability of researchers to categorize members of a family affected by alcoholism into "narrowly defined roles based upon a few salient characteristics." Although it is true that more modern research needs to be done (primarily in more diverse families), it could be argued that the roles are not necessarily "narrow". The roles are constantly being played out by individuals in a family; one individual may take on multiple roles. Consequently, once one member leaves a family, their role is now empty and someone will need to take on that role. The idea that these children must fit the mold of one role is not realistic, and some may exhibit the characteristics of their role(s) more outwardly than others.

\section{Adult Children of Alcoholics (ACOAs)}

Much of the literature concerning ACOAs discusses the prevalence of alcoholism and the added risk of addiction. Although I will not be looking at this during my analysis, it is important to mention that ACOAs do have a higher rate of addiction, specifically to alcohol, than nonACOAs (Chassin, Pitts, DeLucia, \& Todd, 1999). As far as behavior is concerned, ACOAs are written about as a whole; there is not much research that looks at one specific group of ACOAs (for example, those who identified as fulfilling "the hero" role during childhood) to analyze how these roles have impacted their roles and patterns in adulthood, even after they have left their home of origin.

In general, ACOAs are described as being emotionally detached and depressed. They are also described as having difficulty in romantic relationships due to their issues with trust. 
Klostermann et al. (2011) found that ACOAs have a more depressive mood than non-ACOAs, and fewer coping strategies. Dingledine (2000) describes the three biggest issues of ACOAs to be intimacy, locus of control, and shame. They also often have elevated levels of stress and anger, and are more irritable when it comes to accepting others (Hall \& Webster, 2002). ACOAs oftentimes feel and recognize that they are different from non-ACOAs. This in particular plays a big role in their struggle to succeed in intimate relationships. Hall and Webster (2002) claim that ACOAs have emotional turmoil because of their family of origin and may later generate "feelings of low level and chronic self-doubt, questions about ability to handle life challenges, and a propensity toward having a greater number of emotionally upsetting experiences." (p. 208).

\section{Symbolic Interactionism in Relation to COAs and ACOAs}

Symbolic interactionism began developing early on in the 1900's, with pragmatic philosophers such as William James, John Dewey, Charles Pierce, and Josiah Royce (Vander Zanden, 1987). These pragmatists identified the following foundations of the theory: the world is always changing; social structure is constantly changing; meaning does not come from objects, but with the interaction of objects and the person; and ideological commitment to progress and democratic values.

These pragmatists, along with George Herbert Mead, Charles Holton Cooley, William Isaac Thomas, and Herbert Blumer were integral to developing the theory of symbolic interactionism (Smith \& Hamon, 2012). This theory basically states that people define situations based on their own personal experiences and sense of self. At the time, this theory helped people feel more in control of their lives, and taught them that they could change the course of events in society through interaction (Smith \& Hamon, 2012). 
Symbolic interactionism is used in literature to describe how COAs view and attach meaning to alcohol, although it may not be explicitly stated. Although the term "symbolic interactionism" may not always be used, we can see it embedded in the vast majority of literature relating to COAs and ACOAs. For example, any literature that discusses a COA or ACOA's attitude toward alcohol itself is doing so via symbolic interactionism. Zucker, Kinkaid, Fitzgerald, and Bingham (1995) also use symbolic interactionism as they examine alcohol schema acquisition. In their study, they found that three year old COAs are more likely than non-COAs to be able to identify alcoholic beverages in photographs. This is an example of symbolic interactionism because it shows that even as young as three years old, COAs have a different concept of alcoholic drinks than non-COAs (who may not have a concept of it at all). Dingledine (2000) discusses symbolic interactionism when he talks about rituals in the alcoholic family (such as inconsistent mealtimes). Although symbolic interactionism is used in the literature, there is little evidence looking at the roles and patterns of COAs and the maintenance of these roles and patterns for ACOAs as explicitly stated through the lens of symbolic interactionism.

\section{Family Systems Theory in Relation to COAs and ACOAs}

Although the common belief is that family systems theory emerged in the 1960's, concepts that led to its emergence were being discussed long before that. Ernest Burgess, in 1926, referred to the family as "a unity of interacting personalities" which would then lead to the idea of the family being a large, growing, "super-personality" (Smith \& Hamon, 2012). Family systems theory is incredibly complex, but its main ideas revolve around that of the "superpersonality," roles, communication, and family types. 
There is more research on COAs and ACOAs that explicitly discuss family systems theory as a framework for looking at their roles and patterns. Murray Bowen shows up often and seems to be one of the more predominant writers in the field as far as looking at alcoholism through the lens of family systems theory. Many expand on Bowen's work in the field when looking at alcoholism in the family as a codependent system. Prest and Protinsky (1993) state that "codependence emerges from dysfunctional relationship patterns that are primarily rooted in the intergenerational family emotional system.” (p. 359). By discussing the codependent, family systems theory can help to demonstrate how alcoholism affects more than just the identified patient, or the person who manifests most of the symptoms, within a family (Smith \& Hamon, 2012). The experience of other family members, as well as their involvement (i.e. role establishment/maintenance) is what I would like to discuss in order to further this theoretical framework.

\section{Methodology and Analysis}

I will be providing a theoretical analysis of the establishment and maintenance of roles and patterns of COAs and ACOAs. For this analysis, I will be considering this topic through the lenses of symbolic interactionism theory and family systems theory, which will result in a qualitative theoretical analysis. I will use these two theories and apply them to both the roles and patterns originally established by COAs as well as how they are maintained by ACOAs. For symbolic interactionism, I will focus my analysis on the assumption that a) meaning is a central element of human behavior, as well as the concepts of b) symbols, c) social norms, d) rituals, e) roles, f) salience, and g) identity. For family systems theory I will focus on the assumption that a) the locus of pathology is not within the person but is a system dysfunction, b) circular causality guides behavior, c) concepts of equilibrium, d) feedback loops, e) pathological 
communication, and f) roles. I will end by providing critiques of the theories and any theoretical implications that may concern professionals who may be working with COAs and/or ACOAs.

\section{Symbolic Interactionism}

Applying symbolic interactionism to the complex family dynamic of parental alcoholism will allow us to make connections between the behaviors and patterns of COAs and those of ACOAs. In order to explain some of the assumptions and concepts that I will be analyzing, I will use an example of a hypothetical family and apply the assumptions and concepts to this particular example.

The Smith family consists of five members - Dave and Lisa, who are the parents, and Sarah (16), Michael (10), and Catherine (8), the children. Lisa is an alcoholic dependent who has been drinking heavily for the past decade. Dave is in the enabling spouse, and is constantly making sure that he and his children do everything in their power to keep Lisa happy, especially when she has been drinking. Sarah plays the hero role in her family, often having to take care of her brother and sister when her mother has been drinking. This is her most salient role, although she often uses humor around her friends and therefore fulfills the mascot/clown role as well. Michael plays the scapegoat role, often acting out and producing maladaptive behavior in order to get attention from his family. Lastly, Catherine is the lost child. She spends most of her time in her bedroom and rarely engages with the family.

Symbols, according to symbolic interactionism, are anything that we define based on context or the way we view others using them (Smith \& Hamon, 2012). One object could hold several different meanings for a group of people. They are defined differently because they have been witnessed in different contexts or social interactions. Similarly, when we look at one basic 
assumption of symbolic interactionism, "meaning is a central element of human behavior," we learn that people will react to different objects in their lives according to the meaning that they have tied to that object. This meaning is learned through our interactions with others, and will guide our behavior. Due to the overwhelming amount of responsibility that Sarah, in our example family, has taken on, it is likely that her definition of alcohol will be dramatically different than that of a non-COA sixteen year old. Sarah has seen the affects of alcohol on her mother and family unit, and perhaps Sarah will refuse alcohol in the future or be repulsed by it. Here, her behavior would be reflecting the meaning behind the symbol. Another possible situation is that Sarah may learn to use alcohol to cope with her problems with the stress associated with being the family hero, along with the fact that this is the coping mechanism that has been modeled for her. Of course there is always a higher risk for COAs to abuse alcohol than non-COAs in general, but the perception of the individual plays a factor in their symbol construction and their future behavior with that symbol.

According to symbolic interactionism, social norms dictate how you are expected to react in various situations (Smith \& Hamon, 2012). Our interactions with a given group teaches us how to behave in that particular situation. For example, it is likely there is an expectation in the Smith family that no one addresses the issue of alcoholism. Dave, the enabler, has in some way made it clear to his children that this is not an accepted behavior. Perhaps the children are able to talk to extended family or friends about the parental alcoholism in their family, depending on their past interactions with these people, but it is not an appropriate social norm at home. Many social norms can come together in the form of a ritual (Smith \& Hamon, 2012). Family rituals play a large factor when it comes to which role a COA will adopt. A ritual is a set of social norms for a specific situation, such as a holiday. Of course, these rituals can be more frequent 
than that. For Catherine, it may become a ritual that whenever her mother drinks or a family fight breaks out, she escapes to her bedroom. Perhaps Sarah's ritual is to entertain Michael and make sure that he does not act out in this situation. Whatever it may be, this ritual is an expectation for the family and if someone fails to fulfill their part in the ritual, problems may arise. The rituals that we play govern which roles we fulfill in our families. If in an alcoholic family the ritual for the oldest child is to take care of the younger children when the dependent has been using, then this child will likely adopt the hero role. This shows that the social norms and rituals that we adopt or our family places on us during our childhood can have a large impact on which roles we play out in our family.

Once we have adopted a particular role or roles, there is usually one role that is most prominent for us. This is what is called salience. A salient role is an important role for the individual, although it is not always the most important (Smith \& Hamon, 2012). However, the more salient the role, the more time that the individual will invest in that role. In the example of the Smith family, Michael may find attention-seeking to be very important. In order to receive the attention he needs, Michael spends most of his time acting out at home and at school, making his scapegoat role his most salient. The roles that are most salient are the ones that go on to best define us and help us form our sense of identity. That being said, it would make sense to conclude that COAs go into adulthood carrying out the same roles and behaviors that helped them to survive as children. Their roles and coping strategies are carried into adulthood, and they may later realize that what helped them when living in a dysfunctional, alcoholic family may not prove to be helpful in their adult life. Although these strategies may not work for them anymore, ACOAs tend to continue to use these strategies again and again even though there is little to no use for them (Gravitz \& Bowden, 1985). The roles and rules associated with 
symbolic interactionism are progressive for children and may become more rigid and stereotypical in their adult lives. This would mean that overly responsible, "hero"-like children would become overly responsible adults, and so forth. Gravitz and Bowden (1985) argue that the rigidity of these roles and behaviors can oftentimes come from the denial that is going on in the family. Because of this denial, there is "little chance to change the situation" (p. 20).

\section{Family Systems Theory}

Family systems theory argues that a family is more than just several individuals who live together, but instead a group of personalities that make up a larger unity. Analyzing family systems theory will help us to identify how parental alcoholism affects the family in its entirety, and how alcoholism is perpetuated within a family system.

One main assumption of family systems theory is that "the locus of pathology is not within the person but is a system dysfunction." (Smith \& Hamon, 2012). This means that the problem is not one that exists within a particular person, but within the family as a whole. For example, instead of claiming that Lisa is the problem in the Smith family, we need to step back and see how the family as a whole functions. Would it make a difference if we knew that Lisa grew up in an abusive family? Perhaps she was abused because her parents were also abused as children and did not know any other way to cope other than what had been modeled for them. Instead of placing blame on a particular person in the family, systems theory encourages us to find ways in which behavioral cycles can be broken (Smith \& Hamon, 2012). Lisa may have been socialized into a particular role as a child, which now affects the role that she plays as a parent. The role that she plays as a parent will also affect the roles that her children adopt, which will guide and determine their behavior and reinforce their mother's behavior. Here, we can see how family members' roles affect one another and complicate each other, and we can see more 
clearly that placing blame on one individual is not effective. A similar idea is the assumption that "circular causality guides behavior." This is again refuting the idea that one thing causes another. With circular causality, we know that the system impacts its environment, and the environment affects the system in turn (White \& Klein, 2002). This brings our attention to the entire process instead of simply focusing on the content. For example, Lisa may tell herself that one of the reasons she drinks is because she is tired of having to make all of the decisions in the household. She believes that if Dave were able to step up and help her make decisions, she would not be so stressed and would not need to drink. However, Dave believes that by letting Lisa make all of the decisions, he is avoiding conflict that would inevitably cause her to drink more frequently. Here, we are not sure if Dave avoids making decisions because Lisa is an alcoholic, or if Lisa's alcoholism is partly her reaction to Dave's indecisiveness. This is an example of the fact that behaviors, according to family systems theory, are circular. This type of circular causality reinforces roles in the family; every person sees themselves as simply reacting to the other (Smith \& Hamon, 2012).

One concept in family systems theory that is incredibly important when looking at COAs is that of equilibrium, or fulfilling a pattern established and reinforced without awareness. Systems traditionally resist change and seek balance, and when they are able to maintain their own "status quo," and have equilibrium, this is known as homeostasis (Smith \& Hamon, 2012). Although equilibrium and homeostasis can be very comforting for a family, this does not mean that equilibrium is good or healthy for the family. Equilibrium may simply mean that the family feels a sense of stability or consistency, even if it is unhealthy or maladaptive. When families fall into roles and patterns, the equilibrium in the family can be offset is someone tries to move outside of their role. This is generally resisted with some type of feedback loop. Positive 
feedback is a rewarding response when someone is being encouraged to continue their behavior. Negative feedback occurs when a family member moves outside the accepted limits of behavior and the family feels that they need to give a punishing or corrective response in order to reestablish homeostasis. These feedback loops can help family members to push each other back into their designated role. For example, it is known in the Smith household that Lisa's alcoholism is not a topic that is to be discussed within the family. Perhaps Sarah gets tired of being parentified and brings it up to her parents. Her father might show negative feedback by giving her a "look" or by reminding her that she is not allowed to talk about it. This pushes Sarah back into her role and reinforces the rigidity of her acceptable behaviors, and by pushing her back, the family maintains control, but not necessarily health. This being said, the quality of communication among family members is one of the main assumptions in family systems theory.

Pathological communication, according to family systems theory, is a form of unclear or confusing ways of relating with others that contributes to relationship problems (Smith \& Hamon, 2012). One type of pathological communication is mystification, which is when the speaker denies reality and acts as if everything is alright in a situation when that is simply not the case. Mystification was present in the above example, when Sarah's father acted as though her thoughts and issues were invalid; like there was no problem within the family. Mystification may be used as a sense of denial in alcoholic families in order to maintain or achieve a sense of equilibrium. Another form of pathological communication is indirect communication, in which a speaker has trouble stating exactly what it is that they are trying to articulate. One of the children in the Smith family may use indirect communication when trying to articulate their concerns to their parents, because they are afraid of the negative feedback loops that may take place. For example, instead of explicitly approaching the problem, one of the children may be 
too vague or unable to clearly state what it is they are seeking to change. One more type of pathological communication is the double bind, in which the speaker is sending contradictory messages. Here we are looking at both the verbal and non-verbal messages that the speaker is sending. Sarcasm is one example of this, where the speaker's tone seems to send a different message than what their words are communicating. As stated previously, alcoholic families tend to have rituals and patterns around denial, and the use or sarcasm or the double-bind may be a great tool for this. We can witness several types of pathological communication in families with parental alcoholism, and these communication patterns result in low self-esteem (Smith \& Hamon, 2012). Children who grow up in families with dysfunctional communication patterns tend to defend themselves with the same patterns as they age, creating a cycle. Consequently, Gravitz and Bowden (1985) claim that ACOAs generally experience feelings of inadequacy and low self-esteem, perhaps until they are able to end this cycle of pathological communication.

Family systems theory assumes that every member of a family takes on a certain role. Roles are patterns of behavior that are developed through repetitive interaction and fulfill a particular function (Smith \& Hamon, 2012). According to family systems theory, if a person tries to change their role, it will force disruption or feedback loops. For example, in order for Lisa to stop playing the role of the dependent, it is crucial that Dave learn how to stop supporting this role by enabling her. The children would also need to learn how to change and adapt to less enabling roles as well. For this reason, roles are very rigid within families. In order to change them, families need to actively seek transformation as a unit or push-back will occur. Change is uncomfortable for families, and oftentimes maintaining homeostasis by playing out our comfortable role becomes the easier option. However, these roles are so rigid and engrained in COAs that they carry them into adulthood, whether or not these qualities are needed in their 
adult life. The use of theory, especially when it is being applied in a professional setting, can be a great tool when it comes to helping these families learn new, healthier patterns.

\section{Discussion}

\section{Usefulness of Theory Application}

Theories are helpful in general for a variety of reasons when it comes to understanding complex family dynamics. Family theory, in particular, is of use due to the fact that it is intergenerational, ensures a range of ages, and is based on a differing definition of "family" (Smith \& Hamon, 2012). There are several functions that a theory provides, including: 1) descriptive function, in which a theory helps to classify organize and name, 2) sensitizing function, which helps spread awareness of a process or phenomenon, 3) integrative function, which helps us to make connections that may be difficult to see initially, 4) explanatory function, which explains data and allows for predictions to be made, and 5) value function, in which the theory has a value stance that is embedded. Symbolic interactionism and family systems theory are applicable to parental alcoholism in many ways, and it could be argued that both theories serve all of the functions listed above when applied to the family dynamics described. Applying these theories to a family system that experiences parental alcoholism can help us to make connections that are not seen initially, and help to explain the behaviors and roles family members take on, and how these behaviors are valued. Theory allows us to step outside of ourselves and see families from a different perspective, which is a very valuable tool.

\section{Critiquing Symbolic Interactionism and Family Systems Theory}

According to Smith and Hamon (2012), there are seventeen ways that we can critique a theory. A few of the more prominent critiques are for richness of ideas in the theory, whether or 
not the theory is complimentary with others, the clarity of the theory, and the coherence of connections among the concepts being presented.

There are a wide variety of critiques that have been presented around symbolic interactionism and family systems theory. For example, there have been many critiques surrounding the ambiguity of symbolic interactionism, but a vast amount of work has been done in the field to address this and it is not as valid today. One of the more current critiques claims that symbolic interactionism does not pay enough attention to biology (Smith \& Hamon, 2012). Some scholars find that it is important that we address genetic inheritance factors within the framework of symbolic interactionism, which could be important when looking at the genetic predisposition of alcoholism. However, most symbolic interactionists are only concerned with biology as it relates to cognitive functions, which in turn affect one's social interactions. Another concept that symbolic interactionism is said to ignore is power. For example, in a family, two people can have different interpretations of the same interaction. However, it is likely that one of these family members holds more power than the other, or is placed on a higher level of hierarchy. This could potentially be problematic when working with alcoholic families due to the fact that oftentimes the dependent holds the most power because the rest of the family needs a sense of equilibrium. Overall, most researchers agree that symbolic interactionism is best when used as a framework for organization rather than a fully developed theory. Smith and Hamon (2012) state that although there may be some problems or objections to this particular approach, symbolic interactionism has given much to the field of family science and is able to grow and change over time and is particularly helpful when addressing COAs.

Family systems theory faces more legitimate criticisms today. White and Klein (2002) express three concerns when it comes to the application of the theory. The first criticism is 
similar to the one that was brought to symbolic interactionism; the idea that the theory is too ambiguous or vague to be able to test, and that it is more of a model than a true theory. Systems theory argues that their theory is appropriately used in the constructivist worldview, and may be applied for different purposes (Smith \& Hamon, 2012). A second criticism of systems theory is that it is too generalized. Many argue that its abstract nature renders it virtually useless when it comes to application. Here, systems theory uses its integrative function as a defense, claiming that it can make connections between natural and social worlds that other theories cannot. Thirdly, some critics claim that many family theorists cannot separate the correct idea of a system as a model from turning a system into a concrete thing. According to these critics, one needs to remember that the idea of a system is simply a model, not a reality. This is important for professionals working with COAs and ACOAs to remember, however, it could be argued that any theory is prone to reify some of their concepts from time to time. It seems clear that many of these critiques stem from the idea that these theories are not useful in a mathematic sense and are too complex for traditional scientific theory to be dealt with in the same fashion. Because of this, it may be argued that family systems will be most useful in a family communication or family therapy setting.

\section{Implications for the Professional Field}

Symbolic interactionism and systems theory can be applied in any profession that works with children or families. As stated above, one very important way that these theories can be integrated is in a family therapy setting. As we discussed with systems theory, every family member in an alcoholic family plays a role in the dysfunction of the dependent. From a therapy viewpoint, support should be directed at the functioning patterns of the family as a whole. The members of the family who are most resourceful or have the most potential for modifying their 
functioning is the member(s) that the therapy should be directed (Bowen, 1974). Once we are able to change the system, the dependent is helped, even if he or she had no part in the therapy whatsoever. Alcoholism is an extremely difficult pattern to modify, regardless of the method being used, but family systems theory can be a tool to help therapists conceptualize the problem in different ways than they may have in the past. Psychiatrist Murray Bowen (1974) applies systems theory by describing that first he looks at the level of anxiety in a family. Those who are most anxious are most dependent on the drinking person. He describes that "the more the family is threatened, the more anxious they get, the more they become critical, the greater the emotional isolation, the more the alcoholic drinks, the higher the anxiety, the greater the criticism and emotional distance, the more the drinking, et cetera..." (p. 121) Bowen (1974) provides an example of how circular causality and rigidity of roles affect alcoholic families. It is helpful to find the family members who are capable of interrupting the anxiety pattern. Bowen (1974) describes several successful therapy sessions that have "cured" the drinking problem in the family, in which the alcoholic was never present for a single session. For example, there were several instances in which neither parent would attend therapy, so time was spent with a motivated oldest daughter. In these cases, the outcomes were favorable. This showcases the assumption that the locus of pathology does not lie within the person but is a system dysfunction. Once we are able to have a willing member of a family change their behavior, we can start to see changes in the system as a whole. Another approach that Bowen (1974) mentions is to put the focus on the overfunctioning member of the family rather than the identified dysfunctional member. For example, it would be much easier to ask the child in the "hero" role to tone down their overfunctioning than it would be to help the dysfunctional alcoholic increase their 
functioning. This type of approach may also be useful in breaking patterns and roles for the children, teaching them that they do not need to take them into adulthood.

Symbolic interactionism and family systems theory can be applied to other professions as well, such as teaching or social work. I would say that the first step to enhance the understanding for these professionals is to educate professionals on these theories so that they can use them in their own settings. For example, a teacher who had an in depth background of symbolic interactionism or family systems theory may see her students very differently. Instead of judging a child or parent for a particular action, professionals can think more broadly, using locus of pathology or symbols to find that blaming one specific person or situation is not always an effective tool. Social workers may learn how to identify behaviors in a child that are tied to a role or symbol and know what to look for in the parents or be able to identify specific feedback loops that are displayed and then later analyze why they might be present. Theory can play an important role when it comes to helping professionals see outside their own bias or lens, benefitting the populations they serve.

\section{The Writer's Story}

I wrote this paper because I have lived through many of the situations that have been described. In my family, my mother is the dependent and has been an alcoholic for nearly fifteen years. My father has been enabling my mother in every way possible, which is something that I did not see until my research began with family theory. I am the oldest child, and there is a significant age gap between myself and my two younger sisters. I quickly became the family hero and was responsible for taking care of my sisters the majority of the time while my mother drank and my father worked long hours. I was highly parentified and stressed during my 
childhood, blaming my mother for all of our family's problems. As I got older I resented her more, causing more conflict within the family and inevitably, more drinking. My two sisters embodied the scapegoat and lost child roles, but after I left the home, my sister, who had once held the scapegoat role, took over my role as the hero. My research into family theory has enlightened me and enabled me to realize that my mother is not the problem, but part of a larger system dysfunction. I always thought that if her drinking stopped, my family would be perfect. This is simply not the case. I can now see the many levels of circular causality behind her drinking and have been able to see the big picture much more clearly. As an ACOA, I have carried my roles as a child into my adulthood. I am an overly responsible adult, overly critical, and very much in need of control. I hate to be surprised because I want everything to be planned and structured. I have been struggling with Generalized Anxiety Disorder (very common for ACOAs) for a number of years. My exploration of this research has shown me that I can reduce my anxiety levels and stop placing all of the blame on my mother's substance abuse. I have had to analyze how I am perpetuating the dysfunction in my family through my role, and encourage everyone to see a therapist who is familiar with a family systems model. It is likely that my own personal biases have made their way into this paper, as it is so clearly relevant to my life and my family on a very personal level. However, the passion that I have for this topic has propelled me in my thinking, and has surely enhanced the ideas in some way. I look forward to using what I have learned from symbolic interactionism and family systems in my own family, along with my future clients as I enter the career field of family science.

\section{Future Research}

Moving forward, I would love to see research that focuses on perceived family childhood roles reported by ACOAs that can be directly compared with their perceived family adult roles. 
This way we could more easily see if there is at least a perception among ACOAs that certain characteristics were brought into their adulthood, although theoretical analyses indicate that this is certainly true. The field would also benefit if there were more controlled studies that define and categorize role behaviors in COAs. Although there is tentative support for the perceptions of COAs that they are more isolated or opposed to their parents (Rotunda, Sherer, \& Imm, 1995), or that older children often assume parental roles in these families, systematic research for role types of COAs under eighteen is lacking. Additionally, research may be done on therapists who use these theories in their practice, and how often these theories prove to be effective versus whether or not it may cause therapists to label or stereotype certain individuals or families that have been affected by alcoholism. This may be a potential problem of the theories; it is important that those working with families are aware that they are just that - theories, not necessarily realities of every family that is dealing with alcoholism. However, when used in the right way, these theories can help us to conceptualize patterns and behaviors. We can then guide these behaviors in a way that discontinues those that are maladaptive, perhaps making life easier not only for the parents in the family, but also for the COAs as they struggle to enter adulthood and modify the existing patterns that may no longer be needed for their survival. 


\section{References}

Berkowitz, A. \& Wesley, H. (1988). Personality characteristics of children of alcoholics. Journal of Consulting and Clinical Psychology, 56(2), 206-209. doi:10.1037/0022006X.56.2.206

Bowen, M. (1974). Alcoholism as viewed through family systems theory and family psychotherapy. Annals of the New York Academy of Sciences, 233(1), 115-122. doi:10.1111/j.1749-6632.1974.tb40288.x

Burk, J. P. \& Sher, K. J. (1988). The "forgotten children" revisited: Neglected areas of COA research. Clinical Psychology Review, 8(3), 285-302. doi:10.1016/0272-7358(88)90092$\mathrm{X}$

Center for Disease Control and Prevention. (2013). Alcohol and public health. Retrieved from http://www.cdc.gov/alcohol/faqs.htm

Chassin, L., Pitts, S. C., DeLucia, C., \& Todd, M. (1999). A longitudinal study of children of alcoholics: Predicting young adult substance use disorders, anxiety, and depression. Journal of Abnormal Psychology, 108(1), 106-119. doi:10.1037/0021-843X.108.1.106

Corazzini, J. G., Williams, K., \& Harris, S. (1987). Group therapy for adult children of alcoholics: Case studies. The Journal for Specialists in Group Work, 12(4), 156-161. doi:10.1080/01933928708411766

Crawford, R. L. \& Phyfer, A. Q. (1988). Adult children of alcoholics: A counseling model. Journal of College Student Development, 29(2), 105-111.

Dingledine, D. W. (2000). Standing in the shadows: Adult daughters of alcoholic mothers (Ph.D.). Smith College School for Social Work, United States -- Massachusetts.

Gravitz, Herbert L. \& Bowden, Julie D. (1985). Recovery: A Guide for Adult Children of 
Alcoholics. NewYork, New York: Simon \& Schuster, Inc.

Hall, C. W. \& Webster, R. E. (2002). Traumatic symptomatology characteristics of adult children of alcoholics. Journal of Drug Education, 32(3), 195-211.

Hogg, J. A. \& Frank, M. L. (1992). Toward an interpersonal model of codependence and contradependence. Journal of Counseling \& Development, 70(3), 371-375. doi:10.1002/j.1556-6676.1992.tb01618.x

Hussong, A. M., Wirth, R. J., Edwards, M. C., Curran, P. J., Chassin, L. A., \& Zucker, R. A. (2007). Externalizing symptoms among children of alcoholic parents: Entry points for an antisocial pathway to alcoholism. Journal of abnormal psychology, 116(3), 529-542. doi:10.1037/0021-843X.116.3.529

Klostermann, K., Chen, R., Kelley, M. L., Schroeder, V. M., Braitman, A. L., \& Mignone, T. (2011). Coping behavior and depressive symptoms in adult children of alcoholics. Substance Use \& Misuse, 46(9), 1162-1168. doi:10.3109/10826080903452546

Manninen, L., Poikolainen, K., Vartiainen, E., \& Laatikainen, T. (2006). Heavy drinking cccasions and depression. Alcohol and Alcoholism, 41(3), 293-299. doi:10.1093/alcalc/agh246

McKenna, M., Chick, J., Buxton, M., Howlett, H., Patience, D., \& Ritson, B. (1996). The Seccat survey: I. the costs and consequences of alcoholism. Alcohol and Alcoholism, 31(6), 565576.

Murphy, J. P. (1984). Substance abuse and the family. The Journal for Specialists in Group Work, 9(2), 106-112. doi:10.1080/01933928408412064

National Institute on Alcohol Abuse and Alcoholism. (2006). Alcohol alert: Underage drinking. U.S. Department of Health and Human Services. Retrieved from 
http://pubs.niaaa.gov/publications/AA67/AA67.htm

Potter, A. E. \& Williams, D. E. (1991). Development of a measure examining children's roles in alcoholic families: Journal of Studies on Alcohol and Drugs, 52(1), 70.

Rotunda, R. J., Scherer, D. G., \& Imm, P. S. (1995). Family systems and alcohol misuse: Research on the effects of alcoholism on family functioning and effective family interventions. Professional Psychology - Research \& Practice February 1995, 26(1), 95104.

Scharff, J. L., Broida, J. P., Conway, K., \& Yue, A. (2004). The interaction of parental alcoholism, adaptation role, and familial dysfunction. Addictive Behaviors, 29(3), 575581. doi:10.1016/j.addbeh.2003.08.028

Schmidt, C., Klee, L., \& Ames, G. (1990). Review and analysis of literature on indicators of women's drinking problems. British Journal of Addiction, 85(2), 179-192. doi:10.1111/j.1360-0443.1990.tb03069.x

Sher, K. J. (1991). Psychological characteristics of children of alcoholics: Overview of research methods and findings. In M. Galanter, H. Begleiter, R. Deitrich, D. M. Gallant, D. Goodwin, E. Gottheil, ... et al. (Eds.), Recent developments in alcoholism, Vol. 9: Children of alcoholics (pp. 301-326). New York, NY, US: Plenum Press.

Sher, K. J., Walitzer, K. S., Wood, P. K., \& Brent, E. E. (1991). Characteristics of children of alcoholics: Putative risk factors, substance use and abuse, and psychopathology. Journal of Abnormal Psychology, 100(4), 427-448. doi:10.1037/0021-843X.100.4.427

Smith, S.R. \& Hamon, R.R. (2012). Exploring Family Theories. $3^{\text {rd }}$ ed.: New York, New York: Oxford University Press, Inc.

Steinglass, P. (2008). Family systems and motivational interviewing: A systemic-motivational 
model for treatment of alcohol and other drug problems. Alcoholism Treatment Quarterly, 26(1-2), 9-29. doi:10.1300/J020v26n01_02

Vernig, P. M. (2011). Family roles in homes with alcohol-dependent parents: An evidence-based review. Substance Use \& Misuse, 46(4), 535-542. doi:10.3109/10826084.2010.501676

Veronie, L. \& Fruehstorfer, D. B. (2001). Gender, birth order and family role identification among adult children of alcoholics. Current Psychology, 20(1), 53-67. doi:10.1007/s12144-001-1003-6

Werner, E. E. (1986). Resilient offspring of alcoholics: A longitudinal study from birth to age 18 . Journal of Studies on Alcohol and Drugs, 47(01), 34.

White, J.M. \& Klein, D.M. (2002). Family Theories. $2^{\text {nd }}$ ed., Thousand Oaks, California: Sage Publications, Inc.

Wolin, S. J., Bennett, L. A., \& Noonan, D. L. (1979). Family rituals and the recurrence of alcoholism over generations. The American Journal of Psychiatry, 136(4-B), 589-593.

Zucker, R. A., Kincaid, S. B., Fitzgerald, H. E., \& Bingham, C. R. (1995). Alcohol schema acquisition in preschoolers: Differences between children of alcoholics and children of nonalcoholics. Alcoholism: Clinical and Experimental Research, 19(4), 1011-1017. doi:10.1111/j.1530-0277.1995.tb00982.x 